\title{
"Ou isto ou aquilo": comparativo entre a Matemática da Educação Infantil nas Diretrizes e na Base Nacional Comum Curricular
}

\author{
"Or this or that": comparative between the mathematics of kindgarden \\ education in the Guidelines and the Common National Curricular Basis
}

\author{
Giovanna Ellen Oliveira Boni (giovannaboni36@gmail.com) \\ Universidade Federal da Grande Dourados (UFGD).
}

Edvonete Souza de Alencar (edvonete.s.alencar@hotmail.com)

Universidade Federal da Grande Dourados (UFGD), no Departamento de Educação - FAED.

\begin{abstract}
Resumo: O artigo apresenta um estudo documental comparativo nos conteúdos de Matemática da Educação Infantil entre as Diretrizes Curriculares Nacionais para a Educação Infantil e a Base Nacional Comum Curricular. Para subsidiar nossa investigação além dos documentos analisados, realizamos uma busca de artigos científicos que mencionam a Base Nacional Comum Curricular na Educação Infantil. Identificamos semelhanças às experiências solicitadas a este segmento de ensino e observamos complementariedades na especificidade de cada objetivo apresentado na Base Nacional Comum Curricular. Como diferença, percebemos que as Diretrizes Nacionais para a Educação Infantil evidenciam a importância dos contextos significativos.
\end{abstract}

Palavras-chave: Educação Infantil; Matemática; Currículo

Abstract: The article presents a comparative documentary study in the contents of Mathematics of Child Education between the National Curricular Guidelines for Early Childhood Education and the National Curricular Common Base. To support our research beyond the documents analyzed, we conducted a search for scientific articles that mention the National Common Curricular Base in kindgarden Education. We identify similarities to the experiences requested in this segment of education and observe complementarities in the specificity of each objective presented in the National Curricular Common Base. As a difference we realize that the national guidelines for kindgarden Education show the importance of meaningful contexts.

Keywords: kindgarden; Mathematics; Curriculum

\section{INTRODUÇÃO}


[...]Quem sobe nos ares não fica no chão, quem fica no chão não sobe nos ares.

É uma grande pena que não se possa estar ao mesmo tempo nos dois lugares!

Ou guardo o dinheiro e não compro o doce, ou compro o doce e gasto o dinheiro.

Ou isto ou aquilo: ou isto ou aquilo... e vivo escolhendo o dia inteiro! [...]

Não sei se brinco, não sei se estudo, se saio correndo ou fico tranqüilo.

Mas não consegui entender ainda qual é melhor: se é isto ou aquilo.

(MEIRELES, 1964)

Os versos de Cecília Meireles escritos em 1964 iniciam a nossa reflexão sobre os conteúdos curriculares. Realizamos escolhas a todo o momento e não é diferente com os conteúdos nos quais devemos ensinar nos distintos segmentos de ensino. Diante da mudança de legislações, resoluções e de documentos orientadores a prática pedagógica e ao desenvolvimento do ensino, o poema de Meireles (1964) nos leva a questionar: Ou isto ou aquilo? Como orientar nossas práticas pedagógicas diante da diversidade de documentos? Essas reflexões são abordadas neste artigo comparando os conteúdos eou habilidades de Matemática da Educação Infantil. Em específico, neste artigo abordamos dois documentos: as Diretrizes Curriculares Nacionais de Educação Infantil (DCNEI) e a Base Nacional Comum Curricular (BNCC). Nossa escolha pelo segmento se deu por esta ser a primeira fase da educação básica, considerada como uma das mais importantes para o desenvolvimento de habilidades e formação intelectual, social e pessoal do aluno. A seleção dos documentos para análise ocorreu pela identificação de quais seriam os documentos mais recentes da área. Nossas análises nesses documentos serão realizadas tendo como foco a Matemática e como os seus conteúdos eou experiências são apresentados: comparando-os.

Assim, organizamos nosso artigo com a apresentação de um resumo sobre as DCNEI e a BNCC. Trazemos algumas sínteses de investigações que veem sendo realizadas com o intuito de discutir e refletir sobre a BNCC na Educação Infantil e por fim apresentamos como cada documento traz os conteúdos e/ou experiências de 
Matemática, comparando-os. Os artigos selecionados para embasar a pesquisa mostram a importância das ponderações que a BNCC trouxe quanto ao currículo de matemática, a criança e sua identidade própria. Nestes, em comum, explicitou-se a ideia da criança como sujeito histórico social que tem o potencial de desenvolver-se integralmente mediante a propiciação de momentos envolvendo os campos de experiências.

\section{AS DIRETRIZES NACIONAIS DA EDUCAÇÃO INFANTIL}

A Educação Infantil é definida pelas DCNEI (2010) como "a primeira etapa da Educação básica, oferecida em creches e pré-escolas" e tem como intento desenvolver integralmente no seu público alvo, crianças de zero a cinco anos, os aspectos "físico, afetivo, intelectual, linguístico e social, complementando a ação da família e da comunidade" (BRASIL, 2010,p.2). Essa concepção de Educação moldada nas especificidades da infância carrega conjuntamente atrelada a ela, o conceito da criança como um "sujeito histórico e de direitos" que realiza:

[...] Interações, relações e práticas cotidianas que vivencia, constrói sua identidade pessoal e coletiva, brinca, imagina, fantasia, deseja, aprende, observa, experimenta, narra, questiona e constrói sentidos sobre a natureza e a sociedade, produzindo cultura. (BRASIL, 2010, p. 12.)

Este documento é fundamentado pela Resolução n. 5 de 17 de dezembro de 2009, no qual explana sobre os objetivos para organizar as ações pedagógicas desenvolvidas na Educação Infantil, orientando as políticas públicas e a elaboração, planejamento, execução e avaliação de propostas pedagógicas e curriculares de Educação Infantil (BRASIL, 2010, p.11)

Além da definição de Educação Infantil e criança como já explanado, o documento trás reflexões sobre o currículo mencionando que é "o conjunto de práticas que buscam articular as experiências e os saberes das crianças com os conhecimentos que fazem parte do patrimônio cultural, artístico, ambiental, científico e tecnológico" (BRASIL,2010, p.12)

Este documento traz ainda como proposta pedagógica ou o projeto político pedagógico como um plano que define metas e ações para a aprendizagem e o desenvolvimento dos alunos, sendo este elaborado coletivamente.

As Diretrizes trazem normativas quanto à matrícula, faixa etária e jornada de estudo. Estabelecem ainda princípios éticos, políticos e estéticos e orientam quanto a organização do espaço, tempo e materiais. Salientamos ainda que traz considerações 
sobre a importância de propostas pedagógicas que atendam a diversidade e a etniculturalidade. Esta diretriz orienta ainda sobre os processos de avaliação da Educação Infantil e sobre a relação que se deve estabelecer com os anos iniciais do Ensino Fundamental.

Os eixos norteadores da proposta são as interações e a brincadeira, apresentando experiências importantes a serem desenvolvidas nesse segmento de ensino.

\section{A BASE NACIONAL COMUM CURRICULAR}

A BNCC procede da necessidade, reconhecida pelo Ministério da Educação (MEC), da existência de propostas de "direitos e objetivos de aprendizagem e desenvolvimento para os alunos da Educação Básica, pactuada com os Estados, o Distrito Federal e os Municípios." (BRASIL, 2017, p.5). Este documento normativo é o produto de um amplo processo de debates e consultas, disponível para análise da população no geral, tanto em críticas como em sugestões, em busca de corroborar com os princípios de uma perspectiva democrática.

Em 2015, o MEC lançou um texto preliminar como que para uma chamada à sociedade para que houvesse a participação efetiva do cidadão na construção ou reformulação da segunda versão da BNCC, que foi analisada por especialistas, encaminhada para o comitê Gestor da Base Nacional Comum Curricular e também à Reforma do Ensino Médio, para que então fosse, finalmente, disponibilizada em 2016. A terceira versão, à qual utilizamos para consulta, complementa e traz uma revisão da segunda versão, e assim, disponibilizada no ano de 2017.

Tratando-se de um documento que abrange a todas as três etapas da educação básica, a Educação Infantil já se inseria no texto preliminar da BNCC, divergindo das estruturas do Ensino Fundamental e Médio, baseando-se na educação voltada nos chamados Campos de Experiência, que se refere à elaboração, que incluem determinadas práticas sociais e culturais de uma comunidade e as múltiplas linguagens simbólicas que nelas estão presentes (BRASIL, 2015, apud ABRAMOWICZ et al., 2016, p.13).

Estes Campos de Experiências oferecem um processo de ensino e aprendizagem através da vivência, para que assim, as crianças de 0 a 5 anos possam compreender a si 
mesmo e ao mundo, nas conformidades dos campos de naturezas distintas que são "O eu, o outro e o nós", "Corpo, gesto e movimentos", "Traços, sons, cores, imagens", "Espaço, tempo, quantidade, relações e transformações".

Outro pilar que rege o documento normativo voltado para a Educação Infantil na BNCC, é o direito de aprendizagem, formulado a partir dos termos impostos pelas DCNEI para a Educação sobre a especificidade dessa etapa da educação, que é "conviver, brincar, participar, explorar, comunicar e conhecer-se, esferas que interpretam como fundamentais para que as crianças aprendam, e que tem como definição a sua ação de oferecer suporte técnico para a aderência de professores e acadêmicos ao discurso neoliberal.(BRASIL, 2015, apud ABRAMOWICZ et al., 2016, p.12).

A Educação Infantil é a primeira etapa da Educação Básica, onde se enfatiza o brincar como mediador dos processos de aprendizagem, já que

Nessa etapa, as crianças reagem ao mundo fortemente guiadas por suas emoções, buscam conhecer diferentes pessoas, adultos e crianças, adquirem maior autonomia para agir nas práticas cotidianas que envolvem as tarefas de alimentação, de higiene, na integração do educar e do cuidar (BRASIL, 2015, apud ABRAMOWICZ et al, 2016, p. 12).

Desta forma, é possível perceber a criança como um indivíduo curioso, que busca compreender o que ocorre no seu entorno. Os documentos normativos, em específico as DCNEI definem a criança como um "sujeito histórico e de direitos, que interage, brinca, imagina, fantasia, deseja, aprende, observa, experimenta, narra, questiona e constrói sentidos sobre a natureza e a sociedade, produzindo cultura" (BRASIL, 2009), e que para tal definição, os

Eixos estruturantes das práticas pedagógicas [...] são as interações e as brincadeiras, experiências por meio das quais as crianças podem construir e apropriar-se de conhecimentos por meio de suas ações e interações com seus pares e com os adultos, o que possibilita aprendizagens, desenvolvimento e socialização. (BRASIL, 2017, p. 33. grifo nosso)

Desta forma, é possível perceber que o brincar propiciado em atividades que envolvam os campos de experiências, possibilita o desenvolvimento integral da criança. Este enfoque no brincar, veem para firmar que a noção do dito conceito abrange não somente o desenvolvimento do lado criativo da criança, mas todos os outros aspectos 
que se devem desenvolver nessa etapa, como os "aspectos físicos, cognitivos, afetivos, sociais, emocionais, entre outros (BNCC, 2017, p. 53).

\section{O QUE PESQUISAS FALAM SOBRE A BASE NACIONAL COMUM CURRICULAR NA EDUCAÇÃO INFANTIL?}

Para a composição dessa seção, buscamos pesquisas no dossiê Educação Infantil e Base Nacional Comum Curricular da Revistas Debates em Educação da Universidade Federal de Alagoas. Escolhemos esse dossiê temático por conter pesquisas específicas do segmento estudado neste artigo.

Abramowicz et al. (2016) no artigo "Alguns apontamentos: a quem interessa a Base Nacional Comum Curricular para a Educação Infantil?” Abordam as propostas que foram feitas pela BNCC para a Educação Infantil, inquirindo o significado e as forças que permeiam o documento, como a política, social e econômica. O objetivo almejado do artigo foi o de definir pontos de convergência na Educação Infantil. Em uma contextualização histórica, as autoras reconstituem todo o percurso político da trajetória da Educação Infantil, apresentando o assistencialismo e a escolarização. A autora menciona que a Constituição Federal de 1988 assegura a educação como um direito fundamentalmente social e à fixação de conteúdos mínimos para o Ensino Fundamental, porém não é mencionado a Educação Infantil e o Ensino Médio. A Lei de Diretrizes e Bases da Educação Nacional de 1996 traz menções a Educação Infantil e ao Ensino Médio, consolidando-as, juntamente ao Ensino Fundamental, como educação básica. O Plano Nacional de Educação de 2014 propõe a implantação de Diretrizes pedagógicas e a base nacional com um curricular com foco nos direitos e objetivos de desenvolvimento/aprendizagem para os anos que compõem o ensino fundamental e médio, respeitando a diversidade local, regional e estadual. A BNCC, sobre a Educação Infantil, utiliza dos princípios centrais das DCNEI, que são conviver, brincar, participar, explorar, comunicar e conhecer-se (CAMPOS; BARBOSA, 2015, p. 360), para mostrar que essa etapa tem a singularidade de valorizar os campos de experiências de aprendizagens (CAMPOS; BARBOSA, 2015, p. 360). Assim como a experiência é protagonista do processo de desenvolvimento da Educação Infantil, que trazem uma organização interdisciplinar, os elementos específicos das áreas de linguagem, Matemática, Ciências humanas e ciências da natureza também protagonizam o processo. 
O pressuposto principal é o de que a Educação Infantil é, conforme as Diretrizes e Bases Nacionais da Educação Infantil em concomitância a BNCC, uma etapa vinculada às experiências vividas pelas crianças, onde, ao definir certa metodologia em busca de conciliar as diferenças existentes, insere-se no âmbito das políticas neoliberais de elogio à diversidade.

Gobbi (2016) em "Entreatos: precisamos de BNCC ou seria melhor contar com a base? A Base Nacional Comum Curricular de Educação Infantil." Objetiva problematizar a BNCC da Educação Infantil, nesse atual período histórico cujas temáticas voltam-se para os Campos de Experiências. A BNCC traz em seus documentos, que a Educação Infantil deve priorizar o ensino a partir das experiências. Gobbi (2016) leva em consideração a necessidade de refletir as propostas vindas do BNCC já que estas podem vir a ferir expressões culturais particulares a grupos oriundos de sociedades culturais diferentes" (GOBBI, 2016, p. 4). Quanto ao conteúdo da BNCC na Educação Infantil

\footnotetext{
Apresentam-se Direitos de Aprendizagem e Desenvolvimento para cada etapa, referidos às cinco principais ações que orientam os processos de aprendizagem e desenvolvimento, dadas as características dos bebês e crianças e as orientações das Diretrizes Curriculares Nacionais para a Educação Infantil: conviver, brincar, participar, explorar, expressar, conhecer-se. (BRASIL, 2 ${ }^{\mathrm{a}}$ versão, 2016, p.32).
}

A autora menciona que a educação, nas conformidades dos documentos normativos, caracteriza-se por sua natureza etapista, que segmenta os conhecimentos em etapas conforme a faixa etária. Assim Gobbi (2016), deixa sua preocupação quando a essa fragmentação excessiva, pois os conhecimentos não se ampliarão ou se conectarão, ofertando às crianças, pouco efeito quanto à diversidade cultural, social ou econômica das mesmas. Este nos diz que a elaboração do currículo deve ocorrer como resultado de um debate presencial e amplo, onde as metodologias ou planos de aula adequem-se em todas as disciplinas, tornando os conteúdos, sequenciais e interligados. Relata ainda que a Educação Infantil acontece, segundo o art. 3 das DCNEI, na articulação dos saberes e das experiências das crianças com o conjunto de conhecimentos já sistematizados pela humanidade que são patrimônios culturais, artísticos, ambientais, científicos e tecnológicos. Ou seja, a experiência se torna um meio necessário pois fornece sentido às manifestações das crianças. 
Simão (2016) no artigo "Experiências sensoriais, expressivas, corporais e de movimento nos campos de experiências da Base Nacional Comum Curricular para Educação Infantil" busca abordar as concepções de corpo e de como ela se concebe como herança da natureza, biológica, cultural, social e histórica, e de como se busca articular como essas ideias e concepções de corpo se inserem e reverberam em ações pedagógicas e educativas na área da Educação Infantil, além de apresentar como os Campos de Experiências, na proposta da BNCC para a Educação Infantil, dão contornos a esse corpo e as especificidades das experiências sensoriais, expressivas, corporais e de movimento. Relata sobre as legislações e como a Lei de Diretrizes e Bases reconhece a Educação Infantil como a primeira etapa da Educação Básica, e que tem como finalidade o desenvolvimento integral de crianças de zero a seis anos, para isso, sendo necessário, que as ações educativas sejam planejadas, observadas, registradas e avaliadas. Desta forma, a autora nos diz sobre como já é assegurada nas DCNEI de 2009, as práticas pedagógicas devem ocorrer de modo a não fragmentar a criança nas suas possibilidades de viver experiências, na sua compreensão do mundo feita pela totalidade de seus sentidos. Na BNCC para a Educação Infantil, se tem a ideia de que é preciso a ampliação de experiências próximas e cotidianas em direção à apropriação de conhecimentos, ou seja, a proposição organizada de campos de Experiências contempla ofertar maior aprendizado para a criança, sendo essa premissa também presente na DCNEI, em incisos expressos no Art. $9^{\circ}$. Sendo que este artigo expressa que

[...] práticas pedagógicas que compõem a proposta curricular da Educação Infantil devem ter como eixos norteadores as interações e a brincadeira, garantindo experiências em particularidades elencadas em doze incisos. (SIMÃO, p. 3).

Relata ainda que as ferramentas que prescindem o Campo de Experiências, que permite também avaliar o trabalho pedagógico proposto, é: Observação constante e sistemática das experiências; o registro e análise desses registros e das produções das crianças, que permite avaliar o desenvolvimento das suas experiências, seus conhecimentos sobre si sobre o outro e sobre o mundo. No Parecer das DCNEI de 2009, assim como nas propostas na BNCC do Ensino Infantil, é indicado a importância das experiências propostas, seguindo essas ferramentas de forma que não haja uma reproposta de atividades descontextualizadas que visem apenas o desenvolvimento de determinadas habilidades. 
Aquino e Menezes (2016) em "Base Nacional Comum Curricular: tramas e enredos para a infância brasileira" abordam, de forma reflexiva, a segunda versão preliminar do documento BNCC, homologada em 2016 pelo Ministério de Educação e Cultura (MEC). O artigo teve como objetivo trazer questionamentos e problematizações que contribuam para os debates referentes a BNCC e os impactos resultantes dos pressupostos que fazem parte deste documento, no contexto da Educação Infantil. Os autores relatam que a BNCC é um documento normativo e orientador na elaboração das propostas educacionais, com o objetivo de articular no ordenamento legal voltado para a educação nacional com um conjunto de políticas nacionais que sustentam a qualidade social da educação básica. A autora reconhece que as dificuldades referentes a definir uma Base Nacional Curricular Comum a fim de alcançar as experiências das crianças que vão às creches e pré-escolas, e ainda revela que as atuais Diretrizes Curriculares Nacionais para a Educação Infantil também já a enfrentaram quando tais Diretrizes definem "concepções de criança e de infância, instituições de Educação Infantil, proposta pedagógica e currículo e estabelecem a função sociopolítica e pedagógica das instituições de Educação Infantil" (BRASIL, 2016, p. 54). As autoras concluem que a BNCC e a DCNEI se interligam em inúmeros pressupostos existentes em seu documento, como no caso dos princípios considerados fundamentais para a educação da criança pequena, a relação que estabelecem ao ECA (Estatuto da Criança e do adolescente) à garantia dos direitos fundamentais da criança; entende a brincadeira, interações e a identidade em construção como eixos pedagógicos da Educação Infantil; a organização do currículo deve se fundamentar nos princípios éticos, políticos e estéticos, além dos princípios de cuidar e educar; e como a Educação Infantil pode priorizar os campos de experiências ao invés do sistema avaliativo e conteudista.

Maria e Flores (2016) em “A Educação Infantil no contexto da Base Nacional Comum Curricular: em defesa das crianças como seres da natureza, herdeiras das tradições culturais brasileiras" trata sobre o debate de autores quanto a suas posições diante de questionamentos sobre o estabelecimento de uma Base Nacional Comum Curricular, abordando o conteúdo que é previsto nas versões desse documento em termos da relação entre a criança e a natureza, tentando alçar reflexões sobre a abordagem deste material. Consideram que a Educação Infantil é a primeira etapa da educação básica tanto pela BNCC quanto pela DCNEI, o argumento das autoras são o 
de que a BNCC não contempla perspectivas ecológicas e ambientais, como é contemplada nas atuais Diretrizes Curriculares Nacionais para a Educação Infantil, na resolução CEB/CNE 05/09. A BNCC contribui com a construção de uma concepção de currículo voltada para a Educação Infantil onde a interação e brincadeiras são os eixos principais curriculares. Relatam ainda quanto a concepção de natureza, que a autora sugere ser a própria vida e ter ligação direta com a escola, meios estratégicos que atribuam ao local a responsabilidade de não só de transmissão/apropriação de conhecimentos, mas a de ressignificar e fornecer conhecimentos apropriadamente para que a criança possa obter os saberes necessários para conseguir viver em sociedade, diante de inúmeras culturas e diferenças.

Silva e Silva (2016) no artigo "BNCC: um currículo integrador da infância brasileira?", analisam a Base Nacional Comum Curricular a fim de encontrar a existência de uma intenção de tratamento voltado para a infância, quanto à passagem dessa etapa para o Ensino Fundamental. A autora menciona que a realidade do Ensino Fundamental se insere muito brutalmente na vida da criança, e é quando a escola deixa de se preocupar com as brincadeiras lúdicas e passa a valorizar o conteúdo em si, já que precisam seguir um cronograma à risca. Mencionam a divergência de "querer" entre os professores do Ensino Infantil e Fundamental dá-se por, em um desenvolver a fala e outras habilidades da criança, noutro tentar mantê-los calados e submissos em seus lugares. Dizem ainda que conforme a perspectiva histórico-cultural, que se assemelha ao sistema etapista, é considerado que o ser humano possui uma forma específica de aprendizagem, desenvolvida a cada idade avançada de vida. Consideram que aos 3 anos, a criança precisa de atividades que lhe proporcionem experiências para que assim, compreenda o que ocorre e como ocorre as coisas, e é nesta fase que acontece o desenvolvimento dos aspectos intelectuais, físicos, emocionais e morais da criança. Já aos 7, esta mesma criança passa a prestar mais atenção nas explicações antecipadoras do que no uso do tal objeto manuseado pelo adulto. $O$ interesse da criança avança de categoria a cada idade avançada. Na BNCC, é perceptível a preocupação quanto a transição da criança do Ensino Infantil para o Ensino Fundamental, assim, referência que é preciso a ação continua dos processos de aprendizagem das crianças, e que seus desenvolvimentos sejam respeitados na conformidade das faixas etárias sem antecipação de conteúdo. Na Educação Infantil, a BNCC organiza os currículos dentro 
dos Campos de Experiências, enquanto que no Ensino Fundamental, esse currículo passa a ser composto por áreas de conhecimentos. As Áreas de conhecimentos, que contemplam elementos necessários para o processo de ensino-aprendizagem, são: Artes (artes visuais, dança, música, teatro), Educação Física (brincadeiras, jogos, danças, esportes, ginásticas, lutas), Língua Portuguesa (oralidade, escrita, leitura, literatura), Matemática, Ciências da Natureza e Ciências Humanas (História e Geografia). A complexidade do processo educativo se dá, não somente pela quase escassa existência de documentos ou discussões que debatam sobre essa transição do Ensino Infantil para o Ensino Fundamental, mas também pela formação de qualidade dos docentes, onde, geralmente negligenciam seu papel como, além de professor, mediador das duas etapas que divergem seus processos pedagógicos.

Barbosa et al. (2016) em "O que é básico na Base Nacional Comum Curricular para a Educação Infantil?"” Debatem a elaboração da Base Nacional Comum Curricular para a Educação Infantil. Diante de uma rápida contextualização sobre a história da Educação Infantil, pode-se percebê-la como uma etapa que tem assumido várias funções como a de combate a pobreza, local que possibilita às mães o trabalho fora de casa e a prevenção do fracasso escolar no ensino fundamental. Mencionam que na Lei de Diretrizes e Bases, na atualização de sua redação, foi-se exigido uma Base Nacional Curricular voltada para a Educação Infantil.

Art. 26. Os currículos da Educação Infantil, do ensino fundamental e do ensino médio devem ter base nacional comum, a ser complementada, em cada sistema de ensino e em cada estabelecimento escolar, por uma parte diversificada, exigida pelas características regionais e locais da sociedade, da cultura, da economia e dos educandos (grifo nosso).

As autoras consideram que ao definir uma Base Nacional Curricular para a Educação Infantil era uma tarefa que deveria ser elaborada pelo Ministério da Educação (MEC), e as Diretrizes Curriculares Nacionais da Educação Infantil se constituiu na maior referência para a elaboração da proposta da BNCC. Nas DCNEI, o currículo infantil faz parte do patrimônio cultural, artístico, ambiental, científico e tecnológico, e tem como principal, o desenvolvimento integral das crianças. Segundo as autoras ambos os documentos são referências importantes por propiciar a visualização da epistemologia do desenvolvimento com as crianças, pois em seus artigos, em forma de exigência, percebe-se o respeito ao ritmo e saber da criança e assim, não deve ser 
pensada como uma barreira interposta entre educadores e crianças. Enfim, para que a implantação da BNCC seja efetivada, um conjunto de questões fundamentais deve entrar em funcionamento como o corpo discente e o restante dos profissionais que auxiliam no funcionamento; a quantidade de crianças nas quais cada professor é responsável, relação entre família e comunidade; estrutura física, os brinquedos, materiais e livros pedagógicos infantis, etc.

Souza (2016) em "Quais as crianças da Base Nacional Comum Curricular? Um olhar para as "culturas" sem diversidade cultural", analisa a BNCC voltada para a Educação Infantil, na perspectiva cultural, relações étnico-raciais e da interculturalidade. O contexto dessa análise discorre das relações de grupos étnicoraciais, assentamentos rurais, quilombos, comunidades indígenas, pomeranas, ribeirinhas, desenvolvimento o fazer pensar das crianças, em questões de identidade, raça/etnia, gênero, classe, idade e geração. Conforme coloca as Diretrizes Curriculares Nacionais para a Educação Infantil, o currículo é

Conjunto de práticas que buscam articular as experiências e os saberes das crianças com os conhecimentos que fazem parte do patrimônio cultural, artístico, ambiental, científico e tecnológico, de modo a promover o desenvolvimento integral de crianças de 0 a 5 anos de idade (BRASIL, 2010, p. 12).

Para a autora a Base Nacional Comum Curricular, demarca as diferentes etapas da Educação Básica, reconhecendo a especificidade e diversidade nos termos de idade e de aprendizagem. A autora se referencia em Kishimoto (2015), e menciona sobre a valorização da escuta e observação infantil em creches e pré-escolas traduz uma nova forma de pensar o currículo, que se distância da concepção centrada no adulto e de conteúdos fixados antecipadamente, característica ainda presente nas demais etapas da Educação. Assim, a autora salienta sobre a presença da Educação Infantil na Base Nacional é demarcada por uma diferença em relação às demais etapas da educação, e pelo reconhecimento de sua especificidade e diversidade em termos de idade e de aprendizagem. Considera este é um aspecto importante do movimento de inserção da Educação Infantil no currículo nacional, pois aponta para o movimento de defesa das crianças de 0 a 5 anos dos processos fixos e homogeneizantes subsequentes, os quais relegam às crianças o direito ao brincar, a perspectiva da aprendizagem a partir das interações, da imaginação, do faz-de-conta, do movimento. Aqui, no que tange à 
primeira etapa da Educação Básica, evidencia-se a existência de um documento que reconhece a diversidade interna ao próprio Sistema Nacional de Educação.

$\mathrm{O}$ artigo analisa a perspectiva cultural presente na proposta da Base Nacional Comum Curricular (BNCC), no que se refere à Educação Infantil, considerando a abordagem da diversidade, na perspectiva da educação para as relações étnico-raciais (Resolução CNE/CP n. 1/2004) e da interculturalidade. Indagando quais as crianças presentes na BNCC, aborda-se como têm sido inseridas no documento a pluralidade das infâncias. Assim, nos diz que diante da realidade educacional brasileira, que reproduz práticas e discursos monoculturais e eurocêntricos, o modo pelo qual as temáticas relativas à diversidade estão sendo colocadas aponta para retrocessos nas conquistas, em torno de currículos que construam a educação intercultural e o combate à desigualdade racial;

Silva (2017) em “O lúdico e a aprendizagem matemática na educação infantil”, dialoga sobre a matemática ensinada neste segmento de ensino. A autora considera em sua problemática a dificuldade relacionada com os conteúdos de matemática. É ressaltado que podemos encontra-los em diferentes ações do cotidiano:

números, de medidas, fazem operações, interpretam figuras geométricas que transmitem mensagens. Regras de trânsito são sinalizadas com desenhos geométricos, telefones e placas de casas e veículos são numerados, notas e moedas contêm seus valores impressos, os meios de comunicação mostram preços e porcentagens, gráficos e tabelas que apoiam previsões, desenhos arquitetônicos; as pessoas utilizam balanças e fitas métricas para diversos fins, enfim, há uma infinidade de informações que se expressam na linguagem matemática. (p. 12)

Com estes exemplos, a autora menciona sobre a quantidade de vezes as quais as pessoas têm possibilidade de trabalhar com a matemática. $\mathrm{Na}$ educação infantil, primeira etapa da educação básica, que "tem como finalidade o desenvolvimento absoluto das crianças" (p. 13), o brincar é de extrema importância, pois "cria possibilidades de acesso a produções culturais, a criança passa pela fase do imaginário, vai imitar o adulto desenvolvendo o raciocínio e criatividade” (p. 15). A criança tende a aprender com mais facilidade quando lhe é propiciado brincadeiras que tratam sobre determinado assunto, e com a matemática não é diferente, pois a "noção de matemática 
se dá no conjunto de habilidades que a criança desenvolve através do estímulo e o professor deve favorecer situações para que isso acorra.” (p. 16)

Há considerações ainda a esse respeito citadas por Bortolanza e Freire (2018) em "Educação Infantil e a Base Nacional Comum Curricular: concepções de criança, desenvolvimento e currículo", abordam concepções que estão presentes na BNCC, sendo estes termos: criança, de desenvolvimento e de currículo. Ao investigarem a concepção de criança, as autoras trazem as ideias divergentes da criança como um sujeito infantilizado ou considerada um mini adulto, sendo que ambas não oferecem uma identidade própria a criança. Contradizendo essas ideias, a BNCC apresenta a “criança como sujeito social [...] inteiro e (de) desenvolvimento integral" (p. 5), que pensa, sente, se expressa, aprende e socializa, etc. Logo, o sujeito criança é capaz de aprender tudo, basta que o currículo esteja adequado para a sua idade, ou seja

Um currículo não pode ser reduzido ao campo das ideias, a busca pela construção de uma proposta pedagógica significativa consiste num processo a ser assumido coletivamente, o que exige a reflexão e a tomada de decisões coletivas acerca de diferentes aspectos que constituem ou interferem no processo educativo das crianças. (p. 29)

A BNCC, nessa premissa, apresenta eixos que se organizam em níveis de escolaridade divididos nas três faixas etárias de: 0 a 1 ano e seis meses, de 1 ano e sete meses a 3 anos e 11 meses, e de 4 a 5 anos e 11 meses, sendo estes "interações e as brincadeiras" (p. 4), separados nos campos de experiências “o eu, o outro e o nós; corpo, gestos e movimentos; traços, sons, cores e formas; oralidade e escrita; espaços, tempos, quantidades, relações e transformações.” (p. 3). Logo, o currículo deve aderir a identidade da criança como sujeito social, que se desenvolve integralmente a partir de situações e experiencias que lhe são propiciadas.

Diante do que é exposto nos artigos observamos que estes apresentam de modo geral os documentos do BNCC e relacionam com as legislações vigentes em específico com as Diretrizes Curriculares Nacionais para a Educação Infantil, no entanto não abordam sobre os conteúdos matemáticos para esse segmento de ensino.

5. COMPARATIVO: DIRETRIZES CURRICULARES NACIONAIS E BASE NACIONAL COMUM CURRICULAR 
Ao analisarmos os dois documentos identificamos que as DCNEI apresentam experiências objetivas e sucintas que devem ser realizadas com os alunos desse segmento de ensino. Em específico, com relação as experiências de Matemática identificamos duas a serem realizadas com os alunos:

- $\quad$ Favoreçam a imersão das crianças nas diferentes linguagens e o progressivo domínio por elas de vários gêneros e formas de expressão: gestual, verbal, plástica, dramática e musical;

- Recriem, em contextos significativos para as crianças, relações quantitativas, medidas, formas e orientações espaço temporais; (BRASIL, 2010, p.25-26)

A BNCC estrutura os conteúdos de Educação Infantil em campos de experiências, no qual são apresentados objetivos de aprendizagem e desenvolvimento. Os campos de experiências são: Eu, o outro e o nós; corpo, gestos e movimentos; traços, sons, cores e formas; oralidade e escrita; espaços, tempos quantidades, relações e transformações. Cada campo de experiência tem um objetivo para cada faixa etária (zero a 1 ano e seis meses; 1 ano e sete meses a 3 anos e 11 meses; 4 anos a 5 anos e 11 meses). Em nossas observações percebemos que os conteúdos de Matemática estão em diferentes campos de experiências.

No campo de experiências Corpo, gestos e movimentos, percebemos os conteúdos matemáticos, nos objetivos:

Crianças de zero a 1 ano e 6 meses (EI01CG06).

- Utilizar os movimentos de preensão, encaixe e lançamento, ampliando suas possibilidades de manuseio de diferentes materiais e objetos.

Crianças de 1 ano e 7 meses a 3 anos e 11 meses

(EI02CG06).

- Desenvolver progressivamente as habilidades manuais, adquirindo controle para desenhar, pintar, rasgar, folhear, entre outros.

Crianças de 4 anos a 5 anos e 11 meses

(EI03CG06).

- Coordenar com precisão e eficiência suas habilidades motoras no atendimento a seus interesses e necessidades de representação gráfica (BRASIL,2017, p.47)

No campo de experiências "Traços, sons, cores e formas", identificamos os conteúdos matemáticos nos objetivos:

Crianças de zero a 1 ano e 6 meses

(EI01TS02) 
- Traçar marcas gráficas, em diferentes suportes, usando instrumentos riscantes e tintas.

(EI01TS03)

- Utilizar materiais variados com possibilidades de manipulação (argila, massa de modelar), criando objetos tridimensionais.

Crianças de 1 ano e 7 meses a 3 anos e 11 meses (EI02TS02).

- Utilizar diferentes materiais, suportes e procedimentos para grafar, explorando cores, texturas, superfícies, planos, formas e volumes.

- (EI02TS03).

- Expressar-se por meio de linguagens como a do desenho, da música, do movimento corporal, do teatro.

Crianças de 4 anos a 5 anos e 11 meses (EI03TS02).

- Expressar-se livremente por meio de desenho, pintura, colagem, dobradura e escultura, criando produções bidimensionais e tridimensionais. (EI03TS03).

- Apreciar e participar de apresentações de teatro, música, dança, circo, recitação de poemas e outras manifestações artísticas. (BRASIL,2017, p.47)

O campo de experiência "Espaços, tempos quantidades, relações e transformações", aborda em todos os objetivos explicitados os conteúdos matemáticos:

\begin{tabular}{|l|l|l|}
\hline $\begin{array}{l}\text { Crianças de zero a 1 } \\
\text { ano e 6 meses }\end{array}$ & $\begin{array}{l}\text { Crianças de 1 ano e 7 } \\
\text { meses a 3 anos e 11 } \\
\text { meses }\end{array}$ & $\begin{array}{l}\text { Crianças de 4 anos a 5 } \\
\text { anos e 11 meses }\end{array}$ \\
\hline $\begin{array}{l}\text { (EI01ET01) } \\
\text { Explorar e descobrir as } \\
\text { propriedades de objetos } \\
\text { e materiais (odor, cor, } \\
\text { sabor temperatura) }\end{array}$ & $\begin{array}{l}\text { Explorar e descrever } \\
\text { semelhanças e diferenças } \\
\text { entre as características e } \\
\text { propriedades dos objetos } \\
\text { (sonoridade, textura, peso, } \\
\text { tamanho, posição no } \\
\text { espaço). }\end{array}$ & $\begin{array}{l}\text { (EI03ET01) } \\
\text { Estabelecer relações de } \\
\text { comparação entre objetos, } \\
\text { observando suas } \\
\text { propriedades. }\end{array}$ \\
\hline $\begin{array}{l}\text { (EI01ET02) } \\
\text { Explorar relações de causa } \\
\text { e efeito (transbordar, } \\
\text { tingir, misturar, mover e } \\
\text { remover, etc) na interação } \\
\text { com o mundo físico. }\end{array}$ & $\begin{array}{l}\text { Observar, relatar e } \\
\text { descrever incidentes do } \\
\text { cotidiano e fenômenos } \\
\text { naturais (luz solar, vento, } \\
\text { chuva, etc). }\end{array}$ & $\begin{array}{l}\text { Observar e descrever } \\
\text { mudanças em diferentes } \\
\text { materiais, resultantes de } \\
\text { ações sobre eles, em } \\
\text { experimentos e } \\
\text { envolvendo fenômenos } \\
\text { naturais e artificiais. }\end{array}$ \\
\hline $\begin{array}{l}\text { (EI01ET03) } \\
\text { Explorar o ambiente } \\
\text { pela ação e observação, } \\
\text { manipulando, } \\
\text { experimentando e } \\
\text { fazendo descobertas. }\end{array}$ & $\begin{array}{l}\text { Compartilhar, com outras } \\
\text { crianças, situações de } \\
\text { cuidado de plantas e } \\
\text { animais nos espaços da } \\
\text { instituição e fora dela. }\end{array}$ & $\begin{array}{l}\text { (EI03ET03) } \\
\text { Identificar e selecionar } \\
\text { fontes de informações, pra } \\
\text { responder a questões } \\
\text { sobre a natureza, seus } \\
\text { fenômenos, sua } \\
\text { preservação. }\end{array}$ \\
\hline (EI01ET04) & (EI03ET04) \\
\hline (EI02ET04) & \\
\hline
\end{tabular}




\begin{abstract}
Manipular, experimentar, arrumar e explorar o espaço por meio de experiencias de deslocamentos de si e dos objetos.
\end{abstract}

\section{(EI01ET05)}

Manipular materiais diversos e variados para comparar as diferenças e semelhanças entre eles.

Quadro1- Objetivos do campo de experiência "Espaços, tempos quantidades, relações e transformações", parteI.

Fonte: BRASIL, 2016 p.47 \begin{tabular}{l|l} 
Identificar relações & Registrar observações,
\end{tabular}

espaciais (dentro e fora, em cima, embaixo, acima, abaixo, entre e do lado) e temporais (antes, durante e depois).

\section{(EI02ET05)}

Classificar objetos, considerando determinado atributo (tamanho, peso, cor, forma e etc). manipulações e medidas, usando múltiplas linguagens (desenho, registro, por números ou escrita espontânea), em diferentes suportes.

\section{(EI03ET05)}

Classificar objetos e figuras, de acordo com suas semelhanças e diferenças.

\section{Crianças de zero a 1 ano e 6 meses \\ Crianças de 1 ano e 7 meses a 3 anos e 11 meses \\ (EI01ET06) \\ Experimentar e resolver situações-problema do seu cotidiano. \\ (EI01ET07) \\ Vivenciar diferentes ritmos, velocidade e fluxos nas interações e brincadeiras (em danças, balanços, escorregadores, etc).

(EI02ET06) \\ Analisar situações- problema do cotidiano, levantando hipóteses, dados e possibilidades de solução. \\ (EI02ET07) \\ Utilizar conceitos básicos de tempo (agora, antes, durante, depois, ontem, hoje, amanhã, lento, rápido, depressa, devagar). \\ (EI02ET08) \\ Contar oralmente objetos, pessoas, livros etc., em contextos diversos. \\ (EI02ET09) \\ Registrar com números a quantidade de crianças (meninos e meninas) \\ Crianças de 4 anos a 5 anos e 11 meses \\ (EI03ET06) \\ Resolver situações- problema, formulando questões, levantando hipóteses, organizando dados, testando possibilidades de solução. \\ (EI03ET07) \\ Relatar fatos importantes sobre seu nascimento e desenvolvimento, a história dos seus familiares e da sua comunidade, \\ (EI03ET08) \\ Relacionar números às suas respectivas quantidades e identificar o antes, o depois e o entre em uma sequência. \\ (EI03ET09) \\ Expressar medidas (peso, altura, etc.), construindo gráficos básicos.}

Quadro 2- Objetivos do campo de experiência "Espaços, tempos quantidades, relações e transformações", parte II.

Fonte: BRASIL, 2016 p.48 
Notamos assim que ambos os documentos possuem semelhanças quanto aos conteúdos que devem ser desenvolvidos no ensino de Matemática e utilizam como nomenclatura o uso de experiências. No caso das DCNEI estas são mais objetivas e sucintas. Já o BNCC utiliza de campos de experiências específicos que se desdobram em objetivos a serem desenvolvidos e alcançados. Notamos uma diferença nos documentos analisados, as Diretrizes Nacionais para a Educação Infantil evidenciam a importância dos contextos significativos para as atividades do ensino-aprendizagem, tal aspecto não fica claro na Base Nacional Comum Curricular.

\section{ALGUMAS CONSIDERAÇÕES}

Ao analisarmos os documentos observamos que estes orientam as atividades a serem desenvolvidas na Educação Infantil, identificamos alguns estudos que já vêem se debruçando em investigações para poder compreender mais o currículo que envolve este segmento de ensino. Neste artigo, pudemos identificar algumas semelhanças e até complementariedades entre os documentos, pois as Diretrizes ao abordarem de modo objetivo e sucinto os conteúdos a serem desenvolvidos, são complementados pela BNCC, já que ambos utilizam da nomenclatura, experiências, para propor e organizar o currículo da Educação Infantil. Percebemos também que as Diretrizes apontam a importância de experiências significativas para o ensino na Educação Infantil, algo que não é evidenciado de modo claro na BNCC. Inferimos que as Diretrizes permitem uma liberdade do uso curricular para o ensino, aspecto que não é visto na BNCC que apresenta pouca flexibilidade ao uso dos objetivos a serem alcançados em Matemática na Educação Infantil, correndo o risco de negligenciar o direito de brincar e aprender garantido a esses alunos.

Assim, parafraseando Cecília Meireles (1964) “Ou isto ou aquilo: [...] e vivo escolhendo o dia inteiro! [...]Não sei se brinco, não sei se estudo, se saio correndo ou fico tranquilo", nos fazem refletir sobre nossas escolhas em práticas pedagógicas, nossas escolhas curriculares e nossas escolhas diárias. Comparativos como o apresentado neste artigo revelam a necessidade para que se realizem mais estudos comparativos entre diferentes documentos. Este artigo inicia as reflexões sobre dois documentos referenciais para o ensino e aprendizagem do Brasil e que provavelmente 
levarão professores e formadores de professores a pensarem sobre suas práticas pedagógicas utilizando-se para isso de estudos conscientes e críticos dos documentos curriculares.

\section{REFERÊNCIAS}

ABRAMOWICZ, A. et al. Alguns apontamentos: A quem interessa a Base Nacional Comum Curricular para a Educação Infantil? Revista Debates em Educação, Maceió, AL, v. 8, n.16, p. 46-65, jul./dez. 2016.

AQUINO, L. M. L.; MENEZES, F. M. Base Nacional Comum Curricular: Tramas e enredos para a infância Brasileira.Revista Debates em Educação, Maceió, AL, v. 8, n.16, p. 29-45, jul./Dez. 2016.

BARBOSA, M. C. S.; et al. O que é básico na Base Nacional Comum Curricular para a Educação Infantil? Revista Debates em Educação, Maceió, AL, v. 8, n.16, p. 12-28, jul./Dez. 2016.

BORTOLANZA, A. M. E.; FREIRE, Renata Teixeira Junqueira. Educação Infantil e a Base Nacional Comum Curricular: Concepções de criança, desenvolvimento e currículo. Série-Estudos-Periódico do Programa de Pós-Graduação em Educação da UCDB, v. 23, n. 49, p. 67-96, 2018.

BRASIL. Base Nacional Comum Curricular - segunda versão. Brasília: MEC/CONSED/UNDIME, 2016. Disponível em: <http://basenacionalcomum.mec.gov.br/documentos/bncc-2versao.revista.pdf >. Acesso em: 29 de novembro de 2017.

Disponível

Base Nacional Comum Curricular - terceira versão. Brasília, 2017. <http://http://basenacionalcomum.mec.gov.br/images/BNCC_publicacao.pdf>. Acesso em: 29 de novembro de 2017

Base Nacional Comum Curricular - versão preliminar. Brasília, 2015. Disponível em: <http://basenacionalcomum.mec.gov.br/\#/site/conheca>. Acesso em: 29 de novembro de 2017.

Diretrizes Curriculares Nacionais para a Educação Infantil. Brasília: MEC/SEB, 2010.

GOBBI, M. A. Entreatos: Precisamos de BNCC ou seria melhor contar com a Base? A Base Nacional Comum Curricular de Educação Infantil. Revista Debates em Educação, Maceió, AL, v. 8, n.16, p. 118-135, jul./dez. 2016. 
MARIA, L.T.; FLORES, L. R. A Educação Infantil no contexto da Base Nacional Comum Curricular: Em defesa das crianças como seres da natureza, herdeiras das tradições culturais brasileiras. Revista Debates em Educação, Maceió, AL, v. 8, n.16, p. 157-183, jul./dez. 2016.

MEIRELES, C. Ou isto ou aquilo? Global Editora.1964.

SILVA, R. S. O lúdico e a aprendizagem matemática na educação infantil. 2018.

SILVA, S. A. M.; SILVA, G. F. BNCC: Um currículo integrador da infância brasileira? Revista Debates em Educação, Maceió, AL, v. 8, n.16, p. 66-88, jul./dez. 2016.

SIMÃO, M.B. Experiências sensoriais, expressivas, corporais de movimento nos campos de experiências da Base Nacional Comum Curricular para Educação Infantil. Revista Debates em Educação, Maceió, AL, v. 8, n.16, p. 184-207, jul./dez. 2016.

SOUZA, M. L. A. Quais as crianças da Base Nacional Comum Curricular? Um olhar para as "culturas" sem diversidade cultural. Revista Debates em Educação, Maceió, AL, v. 8, n.16, p. 136-156, jul./dez. 2016. 